LA W RENCE LIVERM ORE N A T IO N A L LABORATORY
EFFECTS OF PROCESSING AND POWDER SIZE ON MICROSTRUCTURE AND REACTIVITY IN ARRESTED REACTIVE MILLED AL+NI

E. B. Herbold, J. L. Jordan, N. N. Thadhani

June 13, 2011

Acta Materialia 
This document was prepared as an account of work sponsored by an agency of the United States government. Neither the United States government nor Lawrence Livermore National Security, LLC, nor any of their employees makes any warranty, expressed or implied, or assumes any legal liability or responsibility for the accuracy, completeness, or usefulness of any information, apparatus, product, or process disclosed, or represents that its use would not infringe privately owned rights. Reference herein to any specific commercial product, process, or service by trade name, trademark, manufacturer, or otherwise does not necessarily constitute or imply its endorsement, recommendation, or favoring by the United States government or Lawrence Livermore National Security, LLC. The views and opinions of authors expressed herein do not necessarily state or reflect those of the United States government or Lawrence Livermore National Security, LLC, and shall not be used for advertising or product endorsement purposes. 


\title{
Effects of processing and powder size on microstructure and reactivity in arrested reactive milled $\mathrm{Al}+\mathrm{Ni}$
}

\author{
E.B. Herbold ${ }^{\mathrm{a}, \mathrm{b},{ }^{*},}$ J.L. Jordan ${ }^{\mathrm{a}}$, N.N. Thadhani ${ }^{\mathrm{b}}$ \\ ${ }^{a}$ High Explosives Research and Development Branch, Munitions Directorate, Air Force \\ Research Laboratory, Eglin AFB, FL 32542, USA \\ ${ }^{b}$ School of Materials Science and Engineering, Georgia Institute of Technology, Love \\ Manufacturing Building, 771 Ferst Drive, Atlanta, Georgia 30332 \\ * Corresponding author. Present address: Computational Geosciences Group, Lawrence \\ Livermore National Laboratory, Livermore, CA 94550, USA. Tel.: +1-925-422-1659; fax: +1- \\ 925-423-3886.
}

\section{E-mail address: herbold1@llnl.gov (E.B. Herbold)}

Draft Date: 6/6/2011

\begin{abstract}
Ball-milling Al-metal powders can result in self-sustaining high-temperature synthesis in intermetallic-forming systems. Here, $\mathrm{Al}$ and $\mathrm{Ni}$ powders with similar composition are used to investigate how microstructural differences affect the measured time to reaction between powders of different sizes processed under milling conditions specified by statistically designed experiments. Linear statistical models predicting the time to reaction (TTR) and the change in temperature $(\Delta \mathrm{T})$ are built from these experimental results. The time required to observe a selfsustained high-temperature synthesis of $\mathrm{NiAl}$ with different combinations of the powders and ball-milling conditions vary by almost an order of magnitude. Comparisons of powders milled to times corresponding to percentages of their averaged time to reaction show similar reaction initiation temperatures despite the difference in total milling time. Several distinct arrested reactions within the powder grains exhibit rapid solidification or incomplete diffusion of $\mathrm{Ni}$ into Al forming porous Ni-rich layered structures. The partially reacted grains suggest that the composite laminate particles are not forming intermetallic on the grain scale, but on the localized scale between layers.
\end{abstract}

Keywords: high-energy ball-milling; self-propagating high-temperature synthesis; differential scanning calorimetry; X-ray diffraction 


\section{Introduction}

High energy ball-milling has been used extensively to intimately mix metal-metal or metalmetal-oxide powders. The powder is processed through repeated impacts of a "grinding" media usually made from elastically deforming spherical balls enclosed in a sealed container that produces materials with highly refined microstructures, enhanced strength or meta-stable phases [1-16]. This technique has been shown to synthesize intermetallic compounds resulting from gradual and explosive formation at the grain level [3,4,6,9-13]. A self-sustained hightemperature synthesis (SHS) of intermetallics may release large amounts of heat during intermetallic phase formation on the order of that released by explosives [17]. The gasless reaction from reactive milled $(\mathrm{RM})$ experiments forming nickel-aluminides [3,4,6,810,12,15,16,18], titanium-based alloys [5] and combustion reactions in metal-metal-oxides $[11,13,14]$ in a ball-mill are several examples of materials that exhibit SHS.

The microstructure within ball-milled powder grains is highly heterogeneous and is refined during processing until reaction occurs. The refinement process consists of the cold welding of powder grains within the contact areas of impacting balls with one another or the balls with the walls of the vial $[5,8,21]$. Prior to reaction the particle microstructure may consist of many layers due to the flattening of the particles for materials with relatively high deformability. There are many investigations on the kinetics of reaction in idealized multi-layered intermetallic systems that may be applicable to the reactions observed in ball-milled powder particles $[17,18,22,24,25]$. It was shown in [17] that reaction propagation velocities in sputter deposited $\mathrm{Al} / \mathrm{Ni}$ and $\mathrm{Al} / \mathrm{Monel}$ are affected by the layer thickness, temperature and intermixing at the material interface. Additionally, the heat of reaction was found to be lower for laminate thicknesses less than 50nm due to the amount of interfacial mixing [17]. Atomistic simulations of $\mathrm{Al} / \mathrm{Ni}$ nanolaminates under shock loading have shown that the introduction of voids either at 
the interface of the layers or within the Al enhanced the rate of intermetallic reaction [26]. By comparison, prerequisite conditions for reaction in $\mathrm{Al} / \mathrm{Ni}$ powders observed in high-energy ball milling are a suitable reduction in the layer thickness and it is suggested that solid-state diffusion times are decreased by several orders of magnitude as defect densities increase $[8,27]$.

Recent investigations show that arrested reactive milling (ARM) techniques can be used to ball-mill constituent powders to a point where they are well-blended but have not reacted, which are an important class of material candidates for heat sources in joining applications [17] or additions to explosive materials [20,28-31]. The layers within the particles may exhibit a very high defect density depending on the impact energy of the grinding media against the vial walls and the deformability of the constituent powders, which changes with each subsequent impact.

In our recent work, it was shown that the reaction initiation threshold in mixed and ball-milled $\mathrm{Ni}+\mathrm{Al}$ powders [32] under high-rate mechanical loading depends on the microstructure within the powder particles and the level of strain-hardening, which change as a function of processing time [18]. Comparisons between mixed and ball-milled powders showed a reduction in the mechanically induced reaction initiation for moderate milling times that is attributed, in part, to the high specific surface area between constituent materials. However, upon further milling and corresponding reduction in layer thickness within the powder grains, the reduced ductility resulted in a higher mechanically activated reaction initiation threshold. Thus, an optimum amount of ball milling was found depend on the grain microstructure and the level of strain hardening. This dependence is sensitive to the ball milling process variables, which is addressed in this investigation.

Here we investigate high-energy ball-milling of nominally spherical $\mathrm{Ni}$ and Al powders in an equiatomic ratio and vary particle sizes and ball-milling conditions to compare the 
microstrucural differences and reaction characteristics of ARM materials. The time required to observe SHS with different combinations of the powders and ball-milling conditions shown here vary by almost an order of magnitude [33]. Here the time to reaction is used as a basis for comparison between the powders, which will be useful in both thermal and x-ray analysis. Three materials are selected to determine the averaged time to reaction for given particle sizes and milling conditions to compare the powders as a function of milling-time needed for SHS. The temperature change on the outside of the vial containing the powder is also measured and used to indicate the specific energy release during alloy formation. The resulting NiAl powder grains show signs of melting and void creation, as expected, and several partially reacted powder grains are shown and discussed.

\section{Experimental Methods}

\subsection{Ball-Milling}

For each ball-milling operation, the powders, stainless steel grinding media and process control agent (PCA) were loaded and unloaded in a stainless steel vial within a glove box filled with Ar. Though Ar has been shown to increase the ambient temperature within the vial it is used to prevent nitride or oxide formation (see Chapter 15 in [27]). Four stainless steel vials were used at random to reduce the dependence of milling on any contaminants deposits or difference in roughness on the inside surfaces. It is shown in [34] that contamination is an order of magnitude less using stainless steel vials and grinding media and was reported at $0.35 \% \mathrm{Fe}$ contamination for 8 hours of continuous milling [21]. Each ball-milling experiment is performed with a molar ratio of $\mathrm{Ni}_{0.5} \mathrm{Al}_{0.5}$ with three different $\mathrm{Ni}$ powders (Ni: 5-15 mm, -300 mesh, 150+200, 99.8\% pure, Alfa Aesar) and $\mathrm{Al}$ powders (Al: H2, H30, H50, 99.7\% pure, Valimet, Inc.). The powder was milled in a SPEX-8000 shaker mill (by SPEX CertiPrep® Group) with 
varying amounts of stearic acid as a percentage of the total powder mass $(95 \%$ reagent grade, Sigma Aldrich) [5]. A recent investigation shows that varying the milling intensity by grinding powders with media of different density affects the degree of refinement and subsequent reaction [14]. Here, changing the size of the milling media varies the milling intensity. Fresh grinding media is used for each experiment to aid in the reduction of Fe contamination due to surface deterioration $[8,27]$.

In total, seven variables are considered including: the diameter of the grinding media $\left(d_{b}\right.$ $[\mathrm{mm}]$ ), the charge ratio (i.e. mass of grinding media to the mass of powder, $r_{b p}$ ), total powder mass $\left(m_{p}[\mathrm{~g}]\right)$, controlled temperature $\left(T_{c}\left[{ }^{\circ} \mathrm{C}\right]\right)$, size of the $\mathrm{Ni}$ and $\mathrm{Al}$ powders $\left(d_{\mathrm{Ni}}\right.$ and $\left.d_{\mathrm{Al}}[\mu \mathrm{m}]\right)$ and amount of PCA $\left(m_{\mathrm{PCA}} / m_{p}\right)$. Each variable tested at two different levels would require 128 experiments to quantify single or combined effects these changes have on the measured time to reaction and temperature change of the vial. Design and analysis of experiments principles were used to systematically reduce the number of experiments while maintaining as much information as possible for quantitative analysis [35]. These principles allow us to quantify our results while changing more than one variable at a time (i.e. a factorial design). The term "designed experiments" is used in this paper to acknowledge use of a factorial design. A resolution 3 fractional factorial design of experiments (DOE) with replicated center points is shown in Table 1 where the reduction in the number of experiments is achieved at the expense of aliasing main effects with two factor interactions. A full explanation of this design is beyond the scope of this paper, but can be found in [35]. Regression analysis of the factors affecting the time to reaction is performed with Design Expert software [36].

Two thermocouples (Omega, SA2F-K) with a USB-5201 data logging device (Measurement Computing Corp.) are attached to a $1 \mathrm{~mm} \mathrm{Cu}$ plate mounted between the bottom of the vial and 
the clamp for redundant temperature monitoring with a program written in LabView. The ball-mill is equipped with temperature control using a Cole-Parmer polystat chiller running ethylene glycol and water (1:1 volume ratio) through polyethylene tubing flowing through a custom $\mathrm{Cu}$ coil with 11 turns. The temperature is automatically adjusted via servo-actuated valve to increase or decrease the flow of coolant. The mill motor is turned off automatically at the detection of a specified critical temperature, indicating reaction was achieved (see Fig. 1). A time limit was specified at 8 hours such that the motor would cease operation if reaction had not occurred,. In the event that the mill stopped for any reason other than a reaction before this time, the experiment was repeated to obtain a time to reaction from continuous milling.

\subsection{Powder Characterization}

The particle morphology is visualized using backscattered and secondary electron images from a JEOL JSM-5900LV scanning electron microscope (SEM) and Oxford Link ISIS energy dispersive spectrometer (EDS). The powders are embedded within an epoxy matrix and then polished to investigate the sub-grain microstructure. The powder phase composition was determined using x-ray diffraction results from a Philips X'Pert Pro MPD powder diffractometer operated at $50 \mathrm{kV}$ and $20 \mathrm{~mA}$ with $\mathrm{Cu} \mathrm{K}_{a}$ radiation at $1.5418 \AA$. Soller slits of 0.04 rad with a 10 mm mask were used to limit the axial divergence of the beam. Thermal characterization of the arrested reactive milled powders is performed with a Mettler-Toledo TGA/DSC STARe system at $20 \mathrm{~K} / \mathrm{min}$ with $110 \mathrm{~mL}$ Argon flowing over the furnace and $\mathrm{Al}_{2} \mathrm{O}_{3}$ crucible.

\section{Results}

\subsection{Ball-milling temperature measurements}

The measured results from the designed experiments shown in Table 1 are listed in Table 2. The variation in the measured composition of powders is less than $1 \%$, which should not prohibit 
the intermetallic reaction since it may take place above or below its stoichiometric ratio [9]. The measured mass of the grinding media and powders are given along with the temperature change, measured as the relative height of the temperature spike from the thermocouples shown by the peak with a height of $24{ }^{\circ} \mathrm{C}$ around 9500s in Fig. 1 for Experiment \#29. Table 2 shows that reactions occur within 8 hours for PCA levels of $1 \%$ or lower. Higher levels of stearic acid reduce the level of cold welding at the surface of deforming particles, which promotes microstructural refinement, but increases the time to reaction at and above $4 \%$. It has also been shown recently that increasing levels of PCA from $2 \%$ to $4 \%$ decreases the solubility of supersaturated $\mathrm{Mg}$ in $\mathrm{Al}$ by $5 \%$ at intermediate times of milling between 2 and 8 hours [14].

In the second to last column of Table 2 , the temperature change $(\Delta T)$ due to reaction ranges from $21-45{ }^{\circ} \mathrm{C}$. This quantity is scaled by the mass of the powder and shown in Fig. 2 and plotted as a function of the time to reaction. The value of $\Delta \mathrm{T}$ is the difference between the maximum temperature and the controlled temperature (see the peak amplitude in Fig. 1). Each data point is labeled with its experimental number for comparison with Tables 1 and 2. The point sets marked with $O, \square$, or $\times$ indicate the repetition of experiments 29,32 and 35 , respectively. The $\nabla$ marker indicates the remaining points. Assuming the specific heat is the same for all powders, this figure also indicates the variation in specific energy release detected during reaction, which is approximately $30 \%$. It should be mentioned that reactions using $20 \mathrm{~g}$ of $\mathrm{Ni}$ and $\mathrm{Al}$ were observed within 8 hours with charge ratios as low as 2.5 (see Experiment 17) and in the case of Experiment 19, the powder formed a melt pool within the vial whereas all other reactions resulted in $\mathrm{NiAl}$ powder.

\subsection{Evolution of the powder microstructure}


Experiments 29, 32 and 35 were selected to compare the microstructural differences due to varying particle and milling media sizes and were repeated for determination of the averaged time to reaction (TTR), which are listed in Table 3. Powders milled with these specific milling conditions and particle sizes are designated as ARM1 (data columns 1-3 in Table 3), ARM2 (columns 4-6) and ARM3 (columns 7-9). The time to reaction was reproducible within 10\% and this averaged value is used in subsequent arrested reactive milling experiments to quantify how long the powders have been processed with respect to the known milling time needed for reaction (e.g. ARM1-ARM3 powders were milled for 35\% and 65\% TTR). Subsequent ballmilling experiments were performed as a percentage of these averaged TTR values for microstructural evaluation, which is listed with the powder and milling media mass measurements in Table 4, and processing conditions in Table 1.

In Fig. 3, the initial $\mathrm{Ni}$ and $\mathrm{Al}$ powders are shown in parts (a) and (b) where the particles are nominally spherical and differ in size by about 10 times. Fig. 3(c) shows the microstructure of these powders milled under ARM1 conditions for 35\% TTR. Based on the grayscale color within the particle, small Ni (light gray) and Al particles (darker gray) can be differentiated within the composite powder particles. Void space is also apparent between the $\mathrm{Ni}$ and $\mathrm{Al}$ particles, which may be due to the resistance of the small Ni particles to deformation in comparison with larger particles. In Fig. 3(d) the microstructure is shown for identical powders milled under ARM1 conditions for 65\% TTR. The composite particles are composed fine layers of $\mathrm{Ni}$ and $\mathrm{Al}$ and there are no signs of voids as in (c). It is also apparent that the distribution of components is more uniform in comparison with (c).

Figure 4 shows the initial powder morphology and microstructural development of the powders milled under ARM2 conditions. In comparison with Fig. 3, the Ni particles are about 
20 times larger and there are distinct surface asperities on surface of the larger particles in Fig. 4 (a). The Al particles in Fig. 4 (b) are approximately 20 times smaller than in Fig. 3 (a) and were shipped in air. The smaller particles may introduce a higher $\mathrm{Al}_{2} \mathrm{O}_{3}$ contamination in the milled powders. In (c) the microstructure is shown after being milled for 35\% TTR. It appears that the large Ni particles were deformed much more than the $5 \mu \mathrm{m} \mathrm{Ni}$ particles shown in Fig. 3(a), and their flattened shape resulted in composite particles without gaps between the constituents when comparing Fig. 4 (c) to Fig. 3 (c). Despite the differences between Fig. 3 and Fig. 4 for a milling time of $35 \%$ TTR, the particle morphology is quite similar at $65 \%$ TTR when comparing Fig. 4 (d) and Fig. 3 (d) in terms of layer thickness. The major difference between the two powders (ARM1 and ARM2 powders) is that the Ni layers (light gray color) are much longer than in Fig. 4 (d). The same sized powders from Fig. 4 are used for powders milled with ARM3 conditions where the temperature is slightly higher, and the milling media is much smaller (i.e. lower mass). The evolution of the microstructure in this case is shown in Fig. 5. Powders milled for 35\% TTR show a similar trend as in Fig. 4(c) where the Ni particles are elongated, but have a wavy appearance, which is attributed to the lower energy impacts of the grinding media being unable to completely flatten the initially large Ni particles. The layered microstructure in Figure 5(b) shows significant cracking with and across the direction of the layers. An important part of the ball-milling process is the fracture of particle grains and the cracks shown here may indicate that impact conditions may be insufficient for complete particle fracture. At later milling times the composite $\mathrm{Ni}+\mathrm{Al}$ particles appear to be blended much more in Fig. 5 (d), but Fig. 5(a) shows flattened Ni that are not bonded to any Al. In (d) the microstructure resembles that of a compaction process with small amounts of cold welding in comparison with Figs. 3 and 4 where a finely layered microstructure was observed for longer milling times. The particles milled with 
the smaller milling media may take longer to process into fine layered structures, but the weakly bonded layers are also signs that there may be a lower level of intermixing at the interface of the two layers. This point may be important for powders used for their energy output rather than the resultant intermetallic and is discussed in the thermal analysis [22].

\subsection{Milling energy and time to reaction}

The total energy of the impacts and the time to reaction are used to differentiate the data for the different milling conditions and powder sizes. An estimate for the total milling energy per gram of powder is $[16,37]$

$$
E^{*}=\frac{E_{b} n_{b} f_{b} t_{r}}{m_{p}}
$$

where $E_{b}$ is the impact energy of a single collision, $n_{b}$ is the number of balls, $f_{b}$ is the frequency of impact, $t_{r}$ is the measured time to reaction and $m_{p}$ is the mass of the powder. In [38] the ball velocity within the vial generated by a Spex ${ }^{\circledR} 8000$ high-energy ball-mill was found to depend on its size. Figure 5 in [38] shows this relationship and an approximate expression for their experimental curve for ball sizes ranging from $5-10 \mathrm{~mm}$ is $v_{b}=4.3-160 d_{b}$, where the ball velocity $v_{b}$ and ball diameter $d_{b}$ have units of $[\mathrm{m} / \mathrm{s}]$ and $[\mathrm{m}]$, respectively. An expression for the impact energy of a single ball is $E_{b}=1 / 2 \phi_{b} m_{b} v_{b}^{2}$, where $\phi_{b}$ is proposed in [37] as an efficiency factor related to the number of balls in the vial. Here, we use a similar approach where $\phi_{b}$ is the ratio of the volume of the media and powder to the volume of the empty vial,

$$
\phi_{b}=1-\frac{m_{b} n_{b}}{V_{v} \rho_{b}}-\frac{m_{p}}{V_{v} \rho_{\mathrm{Ni}_{0.5} \mathrm{Al}_{0.5}}}
$$

where $V_{v}=66 \mathrm{~cm}^{3}$ is the volume of the vial, $m_{b}, \rho_{b}=8 \mathrm{~g} / \mathrm{cm}^{3}$ and $n_{b}$ are the mass of a single ball, density and number of balls, $\rho_{\mathrm{Ni}_{0.5} \mathrm{Al}_{0.5}}=5.17 \mathrm{~g} / \mathrm{cm}^{3}$ for the $\mathrm{Ni}_{0.5} \mathrm{Al}_{0.5}$ powder, and $m_{p}$ is the mass of the powder. In [39] the impact frequency was measured by an LVDT in a special ball- 
milling configuration containing only one ball for grinding media. However, since we are using multiple balls for each experiment an estimate for the frequency of impact of each ball is $f_{b}=50$ $\mathrm{s}^{-1}$ since each ball must travel to one flat end of the vial and back each cycle and the period of oscillation of the vial is approximately $25 \mathrm{~s}^{-1}$. Equations (1) and (2) may be evaluated from the data presented in Tables (1) and (2).

Figure 6 shows the total energy (Eq. (1)) plotted as a function of the time to reaction scaled by the charge ratio $C_{R}=m_{b} / m_{p}$. The constant slope of the straight line, $\mathrm{S}$, is taken from Eq. (1),

$$
S=\frac{E_{b} n_{b} f_{b}}{C_{R} m_{p}}=\frac{f_{b} \phi_{b} v_{b}^{2}}{2}
$$

which is the relationship between the amount of free space within the vial and the velocity of the balls for a given frequency. The points above straight line in Fig. 6 marked with $\square$ are experiments with the $3.18 \mathrm{~mm}$ balls. The points marked with $\times$ and $\nabla$ indicate experiments where $5.56 \mathrm{~mm}$ and $7.94 \mathrm{~mm}$ milling media were used. The position of the points $(\square)$ above the line indicates that higher total impact energy is required for similar reaction times using small milling media. Points below the line indicate that less total impact energy is required for similar reaction times using large milling media. This result indicates the larger milling media produces a higher defect density in contrast to the smaller, lighter balls. We observe that the time to reaction depends on the energy per impact separate from the total impact energy.

\subsection{Analysis of variance (ANOVA) of the Designed Experiments}

The time to reaction and the change in temperature due to the reaction were measured for each experiment in Table 1 and are listed in Table 2. There are seven variables present in the design of experiments and the analysis of variance separates the total variability into its component parts using Design Expert software [36]. Table 5 lists the component variability for 
two different linear statistical models that predict the time to reaction (TTR) and the change in temperature during intermetallic formation. The final model for the time to reaction is

$$
\begin{aligned}
t_{r}= & -20000 d_{b}-2000 r_{b p}+700 m_{p} \\
& +100 T_{c}+70 d_{A l}+1000000 m_{P C A} / m_{p}
\end{aligned}
$$

where $t_{r}$ is the time to reaction (TTR) measured in seconds, $d_{b}[\mathrm{~mm}]$ is the diameter of the milling media, $r_{b p}$ is the ball:powder ratio, $m_{p}[\mathrm{~g}]$ is the mass of the powder, $T_{c}\left[{ }^{\circ} \mathrm{C}\right]$ is the control temperature, $d_{\mathrm{Al}}[\mu \mathrm{m}]$ is the nominal size (diameter) of the $\mathrm{Al}$ powder and $m_{\mathrm{PCA}}[\mathrm{g}]$ is the mass of the process control agent. The variation in size of the Ni powder was not statistically significant in this model and was not included in Eq. (4). Equation (4) indicates that the diameter of the balls and the ball:powder ratio are the only two factors contributing to shorter milling times. This was also discussed in the previous section where the deviation of the data above or below Eq. (3) in Fig. 6 was related to the size of the milling media and indicated a dependence of single ball collision energy rather than sum total of impact energy through the ball-milling process. It is interesting that although the control temperatures were not varied greatly, with respect to cryogenic milling with liquid Nitrogen, greater milling time is required for initiation of a self-sustained high temperature synthesis of NiAl for higher vial wall temperatures.

The results shown in Fig. 2 were also used to derive a model that predicts the temperature change due to intermetallic formation,

$$
\begin{aligned}
\Delta T= & -17+34 d_{b}+1.2 r_{b p}+1.8 m_{p} \\
& +0.15 T_{c}-0.16 d_{A l}-0.04 d_{N i}-90 m_{P C A} / m_{p}
\end{aligned}
$$

It is interesting that the initial size of the $\mathrm{Ni}$ particles is a significant factor in this model in contrast to Eq. (4) (see Table 5). Also, there is a dependence of the powder mass in three of the terms $\left(r_{b p}, m_{p}, m_{P C A} / m_{p}\right)$ that balance one another, but the powder mass is the most significant 
factor in the expression. The diameter of the milling media $\left(d_{b}\right)$ the particle sizes $\left(d_{\mathrm{Al}}, d_{\mathrm{Ni}}\right)$ and control temperature $\left(T_{c}\right)$ also contribute to the change in measured temperature during intermetallic formation. The standard error of each term in Eqs. (4) and (5) are given in Table 5 in their respective units.

\subsection{Thermal Analysis}

Results from differential scanning calorimetry (DSC) are shown in Fig. 7 for ARM1-ARM3 powders milled for (a) 35\% TTR and (b) $65 \%$ TTR. The first sign of intermetallic formation occurs at $240^{\circ} \mathrm{C}$ and $220^{\circ} \mathrm{C}$ for (a) and (b) respectively. This is likely the $\mathrm{NiAl}_{3}$ reaction, which is known to be the first meta-stable intermetallic formed followed by $\mathrm{Ni}_{2} \mathrm{Al}_{3}$ then $\mathrm{NiAl}[10,23]$. Is should be mentioned that there is no sign of the first major endothermic peak from stearic acid at $67^{\circ} \mathrm{C}$, which indicates that the contamination from the PCA is not readily observed in thermal analysis [40].

The powders with the highest thermal output per gram milled to $35 \%$ and $65 \%$ TTR are those prepared with ARM1 conditions (Experiments 50 and 53), which are shown in Fig. 3. In this case, the $\mathrm{Al}$ powder was much larger than for ARM2 and ARM3 powders. However, the total milling time of the ARM1 powder is $20 \%$ less than the other two powders. It is possible that the milling time accounts for part of the discrepancy, but the small Al particles initially have 25 times more surface area coated with an oxide layer that is incorporated into the powder, which is another possibility.

The DSC curves for powders milled with ARM2 (Exp. 51 and 54) and ARM3 (Exp. 52 and 55) conditions are approximately the same at times corresponding to $35 \%$ TTR, but ARM3 releases less total energy than ARM2 in Fig. 7(b). It was shown in Fig. 5 (d) that the level of cold-welding was less significant than in Fig. 3 and 4 due to the size of the milling media. One 
possibility for the lower thermal output of ARM3 in Fig. 7(b) is that there is poor mechanical/thermal contact at the interface of the particles (see Fig. 5 (d)), which requires more energy to complete the reaction. Despite the differences between the magnitudes of the DSC data, the initiation temperatures of the reactions are quite similar between these powders milled with three different conditions. This suggests that similar reaction initiation responses can be expected in thermal analysis for powders milled to similar TTR percentages.

\subsection{X-Ray diffraction results}

Figure 8 compares powder X-ray diffraction measurements for six powders milled with ARM1-ARM3 conditions and one from experiment 29 (reacted) shown at the bottom of each subfigure. In Fig. 8 (a) the top three scans are from powders listed in Table 4 as experiment 57 (blue), 59 (red) and 61 (black) corresponding to ARM1-3 conditions milled to 35\% TTR. The middle three scans are from experiment 58 (blue), 60 (red) and 62 (black) corresponding to ARM1-3 conditions milled to $65 \%$ TTR. There is negligible alloy formation for the data corresponding to milling times of $35 \%$ and $65 \%$ TTR and the scan for the reacted powder (i.e. experiment 29) shows that the powder is composed almost entirely of NiAl. This was observed in $[4,16]$ where it is reported that continuous milling may produce alloying at the grain scale, but self-propagating reactions indicated by post-mortem appearance of nickel-aluminides in XRD scans were very sudden. However, increased milling time broadened and decreased the height of the individual $\mathrm{Ni}$ and $\mathrm{Al}$ peaks. In [41] XRD peak abberations are attributed to various sources of strain. Comparing the powders milled for 35\% TTR the full-width-half-maximum values for ARM1 is greater than for ARM2 or ARM3 powders at almost every major peak. This indicates either a higher dislocation density or smaller crystallite size, but may also be characteristic of the starting powders (i.e. small Ni particles). Comparing the powders milled for $65 \%$ TTR the peak 
widths are approximately equal between $2 \theta=37-54^{\circ}$, but a slight difference in asymmetric peak broadening indicates different levels of dislocations, stacking faults, twinning and crystallite size. An investigation of the effects of ball-milling NiAl powder powders beyond SHS can be found in [21].

\section{Discussion}

The DSC data shows a dependence of the thermal performance on microstructure. In applications where ARM materials are being produced for potential chemical energy sources with rapid heat production, the rate of reaction and total energy output are more important than the resulting intermetallic. This means that the processing conditions must balance the size and size distribution of the layered microstructure, the interfacial mixing between components (see Figs. 3-5) as well as the defect density in the constituent materials if the reaction of the powders are to be mechanically initiated. Additionally, the process of particle size reduction by high energy ball milling is capable of producing layer thickness on the order of tens of nanometers while the particle sizes may be on the order of $10-100 \mu \mathrm{m}$. This reduces the need to initially use ultra-fine particles for further reduction since the oxide layer may be considered a non-negligible contaminant for small enough particles.

Figure 9 shows three instances of partially reacted particles from Experiment 29. The compositions indicated in this figure were identified by the EDS at different points within the image. The arrows pointing to NiAl correspond to places where there is a 1:1 ratio of $\mathrm{Ni}$ and $\mathrm{Al}$ by atomic percentage. In addition to the composition provided by the EDS, Fig. 8 shows that the powder from Experiment 29 is composed almost entirely of NiAl. The arrows point to singular compositions of $\mathrm{Ni}$ and $\mathrm{Al}$, which had the lightest and darkest gray color, respectively. The $\mathrm{NiAl}$ color corresponds to a gray tone between $\mathrm{Ni}$ and $\mathrm{Al}$. These three examples typify the occurrence 
of partially reacted particles observed in the other reacted powders (see Fig. 2). In Fig. 9(a) an intermetallic reaction has occurred producing $\mathrm{NiAl}$ (at the bottom) and consuming layered material ahead of the SHS reaction. It is interesting that there is no visible barrier indicating the cause of the arrested reaction. For example, the reaction did not simply reach a crack in the particle or a band of Ni or Al. Void space is visible in the bottom of Fig. 9(a), on the right side of 9 (b) and throughout the particle shown in 9(c). This volume contraction is due to the difference in density between mixed $\mathrm{Ni}+\mathrm{Al}\left(5.17 \mathrm{~g} / \mathrm{cm}^{3}\right)$ and the compound NiAl $\left(5.85 \mathrm{~g} / \mathrm{cm}^{3}\right)$ [4,42,43]. In Fig. 9(a) this void space on the bottom half of the figure indicates the reaction has ceased despite the appearance of thermal contact between the NiAl formations and unreacted material. Figure 9(b) shows unreacted material that is completely surrounded by NiAl. On the left side of the unreacted material the spatial gradation of grayscale color corresponds to compositional differences from $\mathrm{NiAl}$ to $\mathrm{Al}$ or $\mathrm{Ni}$ and there is a clear separation of material on the right side of the unreacted portion. Both (a) and (b) show arrested reaction within grains where the reaction likely ceased due to the insufficient heating of the unreacted material by NiAl.

Figure 9(c) shows an arrested reaction where the particle has excess Ni. Ni-rich bands are shown adjacent to NiAl where the grayscale indicated concentration gradients. While Ni-rich compounds have been synthesized by ball-milling, this particular particle may require further reduction in crystallite size for the subsequent reaction to occur [9].

The details shown by Fig. 9 elucidate the processes occurring during explosive reaction within ball-milled particles. The partially reacted grains suggest that the composite particles are forming an intermetallic between layers within the particle and not at the grain scale.

\section{Conclusions}


The measured time to reaction and change in temperature during SHS of NiAl were investigated with powders composed of equiatomic $\mathrm{Ni}+\mathrm{Al}$ of different sizes processed under different milling conditions specified by statistically designed experiments. Ball-milling conditions and powder particle sizes of Al-Ni powders were varied and linear statistical models predicting the time to reaction (TTR) and the change in temperature $(\Delta \mathrm{T})$ were found. The time required to observe SHS with different combinations of the powders and ball-milling conditions vary by almost an order of magnitude. The time to reaction depends on the energy per impact separate from the total impact energy. Comparisons of powders milled to times corresponding to percentages of their averaged time to reaction show similar reaction initiation temperatures despite the difference in total milling time. Several distinct arrested reactions within the powder grains show explosive reactions with rapid solidification or incomplete diffusion of $\mathrm{Ni}$ into $\mathrm{Al}$ forming porous partially reacted Ni-rich layered structures. The partially reacted grains suggest that the composite laminate particles are not forming intermetallic on the grain scale, but on the localized scale between layers.

\section{Acknowledgements}

EBH would like to thank the Florida Institute for Research in Energetics (FIRE) for support and J.M. Scott for adding the temperature control capability to the ball mill. EBH would also like to thank R. Huffman and D.W. Richards for assistance with DSC and XRD scans. Funding for this research was provided by the University of Florida through the task order 9-0015 from AFRL at Eglin AFB, Contract No. FA8651-08-D-0108. This work performed under the auspices of the U.S. Department of Energy by Lawrence Livermore National Laboratory under Contract DE-AC52-07NA27344. 


\section{References}

[1] Benjamin JS. Metall Trans 1970;1:2943.

[2] Gilman PS, Benjamin JS. Annu Rev Mater Sci, 1983;13:279.

[3] Ivanov E, Grigorieva T, Golubkova G, Boldyrev V, Fasman AB, Mikhailenko SD, Kalinina OT. Mat Lett, 1988;7:51.

[4] Atzmon M. Phys Rev Lett 1990;64:487.

[5] Suryanarayana C, Froes FH. Adv Mater, 1993;5:93.

[6] Cardellini F, Mazzone G, Vittori Antisari M. Acta Mater, 1996;4:1511.

[7] Koch CC. NanoStructured Mat, 1997;9:13.

[8] Thadhani NN. "Mechanochemical synthesis of intermetallic compounds", 2002; in, Intermetallic compounds: principles and practice, edited by J. H. Westbrook, R. L. Fleischer (John Wiley \& Sons, 2002).

[9] Portnoy VK, Blinov AM, Tomilin IA, Kusnetsov VN, Kulik T. J Alloys Comp, 2002;336:196.

[10] Zhu HX, Abbaschian R. J Mat Sci, 2003;38:3861.

[11] Schoenitz M, Ward T, Dreizin EL, Mater Res Soc Symp Proc, 2004;800:AA2.6.1.

[12] Moshksar MM, Mirzaee M. Intermetallics, 2004;12:1361.

[13] Umbrajkar SM, Schoenitz M, Dreizin EL, Propellants Explos Pyrotech, 2006;31:382.

[14] Umbrajkar SM, Schoenitz M, Dreizen EL. J Alloys Comp, 2005;402:70.

[15] Morsi K, Shinde S, Olevsky EA. J Mater Sci, 2006;41:5699.

[16] Joardar J, Pabi SK, Murty BS. J Alloys Comp, 2007;429:204.

[17] Shteinberg AS, Knyazik VA. Pure \& Appl Chem, 1992; 64:965.

[18] Herbold EB, Thadhani NN, Jordan JL. J Appl Phys, 2011;109:066108. 
[19] Dunbar E, Thadhani NN, Graham RA. J Mat Sci, 1993;28:2903.

[20] Boslough MB. Chem Phys Lett, 1989;160:618.

[21] Chen T, Hampikian JM, Thadhani NN. Acta Mater, 1999;47:2567.

[22] Mann AB, Gavens AJ, Reiss ME, Van Heerden D, Bao G, Weihs TP. J Appl Phys, $1997 ; 82: 1178$.

[23] Colgan EG, Nastasi M, Mayer JW. J Appl Phys, 1985;58:4125.

[24] Shteinberg AS, Lin Y-C, Son SF, Mukasyan AS. J Phys Chem, 2010;114:6111.

[25] Mukasyan AS, White JDE, Kovalev DY, Kochetov NA, Ponomarev VI, Son SF. Physica B, 2010;405:778.

[26] Zhao S, Germann TC, Strachan A. J Chem Phys, 2006;125:164707.

[27] Suryanarayana C, Mechanical Alloying and Milling, 2004;CRC Press.

[28] Eakins DE, Thadhani NN. Int Mat Rev, 2009;54:181.

[29] Crone JC, Knap J, Chung PW, Rice BM. Proceedings of the 14th Symposium (International) on Detonation, 2010;ID\#30026.

[30] Armstrong RW, Baschung B, Booth DW, Samirant M. Nano Lett, 2003;3:253.

[31] Reeves RV, White JDE, Mukasyan AM, Son SF. Shock compression of condensed matter2009, Melville, 2009;1195:466.

[32] The powders investigated in [41] are identical to those discussed herein.

[33] This is shown in Table 2 by comparing the time to reaction values from experiments 10 and 17.

[34] DeCastro CL, Mitchell BS. Nanoparticles from Mechanical Attrition, 2002;in Synthesis, Functionalization and Surface Treatment of Nanoparticles, edited by M.-I. Baraton, American Scientific Publishers. 
[35] Montgomery DC. Design and Analysis of Experiments, 5th Ed, 2001; John Wiley \& Sons, Inc. New York.

[36] http://www.statease.com/dx8descr.html

[37] Murty BS, Mohan Rao M, Ranganathan S. Acta Metall Mater, 1995;43:2443.

[38] Bassett D, Matteazzi P, Miani P. Mat Sci Eng, 1994;A174:71.

[39] Chen Y, Bibole M, Le Hazif R, Martin G. Phys Rev B, 1993;48:14.

[40] Jaw KS, Hsu CK, Lee JS. Thermo Acta, 2001;367-368:165.

[41] Ungar T. Scripta Mat, 2004;51:777.

[42] Villars P, Calvert D, Pearson's Handbook of Crystallographic Data for Intermetallic Phases (American Society for Metals, Metals Park, OH), Vol. II, 1985:1038.

[43] Miracle DB. Acta Metall Mater, 1993; 41:649. 


\section{Figure Captions}

Figure 1: Typical temperature measurements from the thermocouples during ball-milling taken from experiment 29 . The two curves marked by (1) are the temperature measured at the bottom (top curve) and top (bottom curve) of the cylindrical vial. The temperature profile of the coolant entering (curve (2)) and leaving (curve (3)) the cooling coil.

Figure 2: The measured temperature change from reaction during milling is scaled by the mass of the powder and plotted as a function of the time to reaction. The value of $\Delta \mathrm{T}$ is the difference between the maximum temperature and the controlled temperature (see the peak amplitude in Fig. 1). Each data point is labeled with its experimental number for comparison with Tables 1 and 2. The point sets marked with $\bigcirc, \square$, or $\times$ indicate the repetition of experiments 29, 32 and 35, respectively. The $\nabla$ marker indicates the remaining points. Assuming the specific heat

is the same for all powders, this figure also indicates the variation in specific energy release detected during reaction, which is approximately $30 \%$.

Figure 3: Initial powder morphology and microstructural evolution of powders milled with ARM1 ball-milling conditions (see Tables 1 and 4). (a) 5-15 $\mu \mathrm{m}$ Ni powder. (b) H50 Al powder. (c) Unseived ARM1 powder milled for $35 \%$ TTR (58 min.). The milled particles have significant porosity and some of the Ni (light-gray) particles are only slightly deformed. (d) show unseived ARM1 powder milled for 65\% TTR (108 min.). The porosity observed in (c) is no longer visible and the Ni particles are heavily deformed.

Figure 4: Initial powder morphology and microstructural evolution of powders milled with ARM2 ball-milling conditions (see Tables 1 and 4). (a) and (b) show $100 \mu \mathrm{m}$ Ni particles and H2 Al particles, respectively. (c) The particle morphology is shown for the powders when milled for $74 \mathrm{~min}$. (35\% TTR). The composite particles are flake-like without visible porosity. (d) The powder particles are shown when milled for $137 \mathrm{~min}$. (65\%). The laminate structure has been refined and the $\mathrm{Ni}$ is dispersed well throughout the particles.

Figure 5: Initial powder morphology and microstructural evolution of powders milled with ARM3 ball-milling conditions (see Tables 1 and 4). (a) and (b) Powder microstructure for powders milled for $71 \mathrm{~min}$. (35\% TTR) with small (light) milling media. The initial powders are identical to (a) and (b) from Fig. 4. Cracks are clearly shown in larger particle agglomerates shown in (b) and the Ni powder is flattened into jagged rod or plate forms. (c) and (d) 
Powders milled for 132 min. (65\% TTR) showing further reduction of Ni particles. However, cracks and incomplete cold-welding is apparent in the large particle depicted in (d).

Figure 6: The total energy is plotted as a function of the time to reaction scaled by the charge ratio. The slope of the straight line is given by Eq. (3). The points above this line marked with $\square$ are experiments with the $3.18 \mathrm{~mm}$ balls. The points marked with $\times$ and $\nabla$ indicate that the $5.56 \mathrm{~mm}$ and $7.94 \mathrm{~mm}$ milling media were used.

Figure 7: DSC results for the milled powders. (a) Powders from experiments 50, 51 and 52 using ARM1, ARM2 and ARM3 conditions are compared where each is milled for 35\% TTR. The initiation temperature is not clearly defined, but is estimated between $400-450{ }^{\circ} \mathrm{C}$. (b) Powders from experiments 53, 54 and 55 using ARM1, ARM2 and ARM3 conditions are compared where each is milled for $65 \%$ TTR. Two distinct reactions are present indicating the difference in reaction kinetics as a function of milling time for similar powders. All scans produced from a heating rate of $20 \mathrm{~K} / \mathrm{min}$. with $110 \mathrm{~mL} / \mathrm{min}$ Ar flow.

Figure 8: XRD scans for powders six powders milled with ARM1-ARM3 conditions and one from experiment 29 (reacted) shown at the bottom of each subfigure. (a) The top three scans are from powders listed in Table 4 as Exp\# 57 (blue), 59 (red) and 61 (black) corresponding to ARM1-3 conditions milled to 35\% TTR. The middle three scans are from Exp\# 58 (blue), 60 (red) and 62 (black) corresponding to ARM1-3 conditions milled to 65\% TTR. The top, middle and bottom scans are shifted arbitrarily for comparison. (b)-(e) The same seven scans are plotted and shifted vertically to highlight the difference in four different Bragg peaks. The $\square, \nabla$ and * indicate the presence of Al, Ni and NiAl, respectively.

Figure 9: BEC image of partially reacted powder agglomerate for experiment 29. (a) The bottom portion is NiAl and the darker gray is $\mathrm{Al}$ and the light gray is $\mathrm{Ni}$. The NiAl is shown as small separated grains at the bottom of the figure. The reaction propagation moved from the bottom to the top of the image before being arrested. (b) A small amount of powder is completely surrounded by intermetallic NiAl. The reaction sopped along the right side through the separate surfaces, but the propagating reaction ceased during reaction on the left. (c) Arrested reaction within a particle where there is a clear concentration gradient from $\mathrm{Ni}$ to $\mathrm{NiAl}$. 
Table 1: Experimental plan for milling 1:1 Ni + Al powders. Experiments 17-39 are part of the designed experiments. The PCA was stearic acid $\left(\mathrm{C}_{18} \mathrm{H}_{36} \mathrm{O}_{2}\right)$ and was added as a percentage of the total powder mass.

\begin{tabular}{|c|c|c|c|c|c|c|c|}
\hline Exp. \# & $\begin{array}{l}\text { Ball } \\
\text { Dia. }\end{array}$ & $\begin{array}{l}\text { Charge } \\
\text { Ratio } \\
\end{array}$ & $\begin{array}{l}\text { Powder } \\
\text { Mass } \\
\end{array}$ & $\begin{array}{l}\text { Control } \\
\text { Temp } \\
\end{array}$ & Al & $\mathbf{N i}$ & $\%$ PCA* \\
\hline & $\mathrm{mm}$ & $\mathrm{x}: 1$ & $\bar{g}$ & ${ }^{\circ} \mathrm{C}$ & $\mu \mathrm{m}$ & $\operatorname{mesh}[\mu \mathrm{m}]$ & $\%$ \\
\hline 10 & 5.56 & 10 & 10 & 32 & 50 & $-150+200$ & 1 \\
\hline 17 & 7.94 & 2.5 & 20 & 32 & 50 & $-150+200$ & 1 \\
\hline 18 & 3.18 & 5.5 & 20 & 32 & 50 & {$[5-15]$} & 7 \\
\hline 19 & 7.94 & 5.5 & 20 & 32 & 2 & [5-15] & 1 \\
\hline 22 & 5.56 & 4.0 & 15 & 27 & 30 & -300 & 4 \\
\hline 21 & 3.18 & 2.5 & 20 & 21 & 2 & {$[5-15]$} & 1 \\
\hline 23 & 3.18 & 5.5 & 10 & 21 & 2 & [5-15] & 7 \\
\hline 24 & 7.94 & 2.5 & 20 & 21 & 50 & {$[5-15]$} & 7 \\
\hline 25 & 3.18 & 2.5 & 10 & 21 & 50 & $-150+200$ & 7 \\
\hline 26 & 7.94 & 2.5 & 10 & 32 & 2 & {$[5-15]$} & 7 \\
\hline 27 & 5.56 & 4.0 & 15 & 27 & 30 & -300 & 4 \\
\hline 28 & 7.94 & 5.5 & 10 & 32 & 50 & $-150+200$ & 7 \\
\hline $\begin{array}{l}29,43,46,50, \\
51,57,58\end{array}$ & 7.94 & 5.5 & 10 & 21 & 50 & {$[5-15]$} & 1 \\
\hline 30 & 3.18 & 5.5 & 20 & 21 & 50 & $-150+200$ & 1 \\
\hline 31 & 5.56 & 4.0 & 15 & 27 & 30 & -300 & 4 \\
\hline $\begin{array}{l}32,44,47,52, \\
53,59,60\end{array}$ & 7.94 & 2.5 & 10 & 21 & 2 & $-150+200$ & 1 \\
\hline 33 & 3.18 & 2.5 & 10 & 32 & 50 & [5-15] & 1 \\
\hline 34 & 7.94 & 5.5 & 20 & 21 & 2 & $-150+200$ & 7 \\
\hline $\begin{array}{l}35,45,48,54 \\
55,61,62\end{array}$ & 3.18 & 5.5 & 10 & 32 & 2 & $-150+200$ & 1 \\
\hline 36 & 3.18 & 2.5 & 20 & 32 & 2 & $-150+200$ & 7 \\
\hline 39 & 5.56 & 4.0 & 15 & 27 & 30 & -300 & 0.5 \\
\hline
\end{tabular}


Table 2: Sample preparation measurements corresponding to the designed experiments presented in Table 1. Temperatures in parenthesis indicate the temperature change due to the intermetallic reaction during continuous ball-milling. The time to reaction indicates that many of the experiments were terminated at the specified 8-hour time limit.

\begin{tabular}{|c|c|c|c|c|c|c|}
\hline Exp. \# & $\begin{array}{l}\text { Mass } \\
\text { Balls }\end{array}$ & $\begin{array}{l}\text { Mass } \\
\text { Al }\end{array}$ & $\begin{array}{l}\text { Mass } \\
\mathrm{Ni}\end{array}$ & $\begin{array}{l}\text { Mass } \\
\text { PCA }\end{array}$ & $\begin{array}{l}\text { Mean } \\
\text { Temp. } \\
(\Delta \mathrm{T})\end{array}$ & $\begin{array}{l}\text { Time To } \\
\text { Reaction }\end{array}$ \\
\hline & $\mathrm{g}$ & $\mathrm{g}$ & $\mathrm{g}$ & $\mathrm{g}$ & ${ }^{\circ} \mathrm{C}$ & $\mathrm{S}$ \\
\hline 10 & 100 & 3.15 & 6.85 & 0.10 & $32(23)$ & 4740 \\
\hline 17 & 49.98 & 6.299 & 13.702 & 0.200 & $32(45)$ & 25416 \\
\hline 19 & 109.6 & 6.299 & 13.702 & 0.201 & $32(37)$ & 15588 \\
\hline 22 & 60.28 & 4.718 & 10.261 & 0.592 & 27 & $>28800$ \\
\hline 21 & 50.00 & 6.268 & 13.800 & 0.197 & 21 & $>28800$ \\
\hline 23 & 55.00 & 3.138 & 6.812 & 0.707 & 21 & $>28800$ \\
\hline 24 & 49.81 & 6.285 & 13.704 & 1.412 & 21 & $>28800$ \\
\hline 25 & 25.00 & 3.142 & 6.844 & 0.702 & 21 & $>28800$ \\
\hline 26 & 25.84 & 3.149 & 6.834 & 0.699 & 32 & $>28800$ \\
\hline 27 & 60.28 & 4.719 & 10.331 & 0.594 & 27 & $>28800$ \\
\hline 28 & 55.84 & 3.145 & 6.847 & 0.700 & 32 & $>28800$ \\
\hline 29 & 55.91 & 3.145 & 6.854 & 0.103 & $21(24)$ & 9525 \\
\hline 30 & 110.0 & 6.291 & 13.703 & 0.200 & $21(37)$ & 21065 \\
\hline 31 & 60.29 & 4.721 & 10.276 & 0.601 & 27 & $>28800$ \\
\hline 32 & 25.93 & 3.156 & 6.849 & 0.098 & $21(25)$ & 11696 \\
\hline 33 & 25.00 & 3.147 & 6.846 & 0.105 & 32 & $>28800$ \\
\hline 34 & 110.0 & 6.301 & 13.705 & 1.395 & 21 & $>28800$ \\
\hline 35 & 54.97 & 3.146 & 6.855 & 0.106 & $32(22)$ & 12708 \\
\hline 36 & 50.02 & 6.297 & 13.702 & 1.399 & 32 & $>28800$ \\
\hline 39 & 60.29 & 4.723 & 10.275 & 0.085 & $27(28)$ & 12454 \\
\hline 43 & 55.76 & 3.149 & 6.848 & 0.105 & $21(22)$ & 10951 \\
\hline 44 & 25.99 & 3.152 & 6.854 & 0.102 & $21(23)$ & 12534 \\
\hline 45 & 54.99 & 3.147 & 6.849 & 0.100 & $32(21)$ & 11948 \\
\hline 46 & 55.99 & 3.147 & 6.851 & 0.098 & $21(21)$ & 9412 \\
\hline 47 & 25.907 & 3.149 & 6.849 & 0.109 & $21(22)$ & 13665 \\
\hline 48 & 54.991 & 3.152 & 6.849 & 0.100 & $32(21)$ & 11946 \\
\hline
\end{tabular}


Table 3: Experimental results for milling $\mathrm{Ni}+\mathrm{Al}$ powders. Each column lists the milling parameters and measured results of the repeated experiments to determine the average time to reaction (TTR) and the standard deviation from this value.

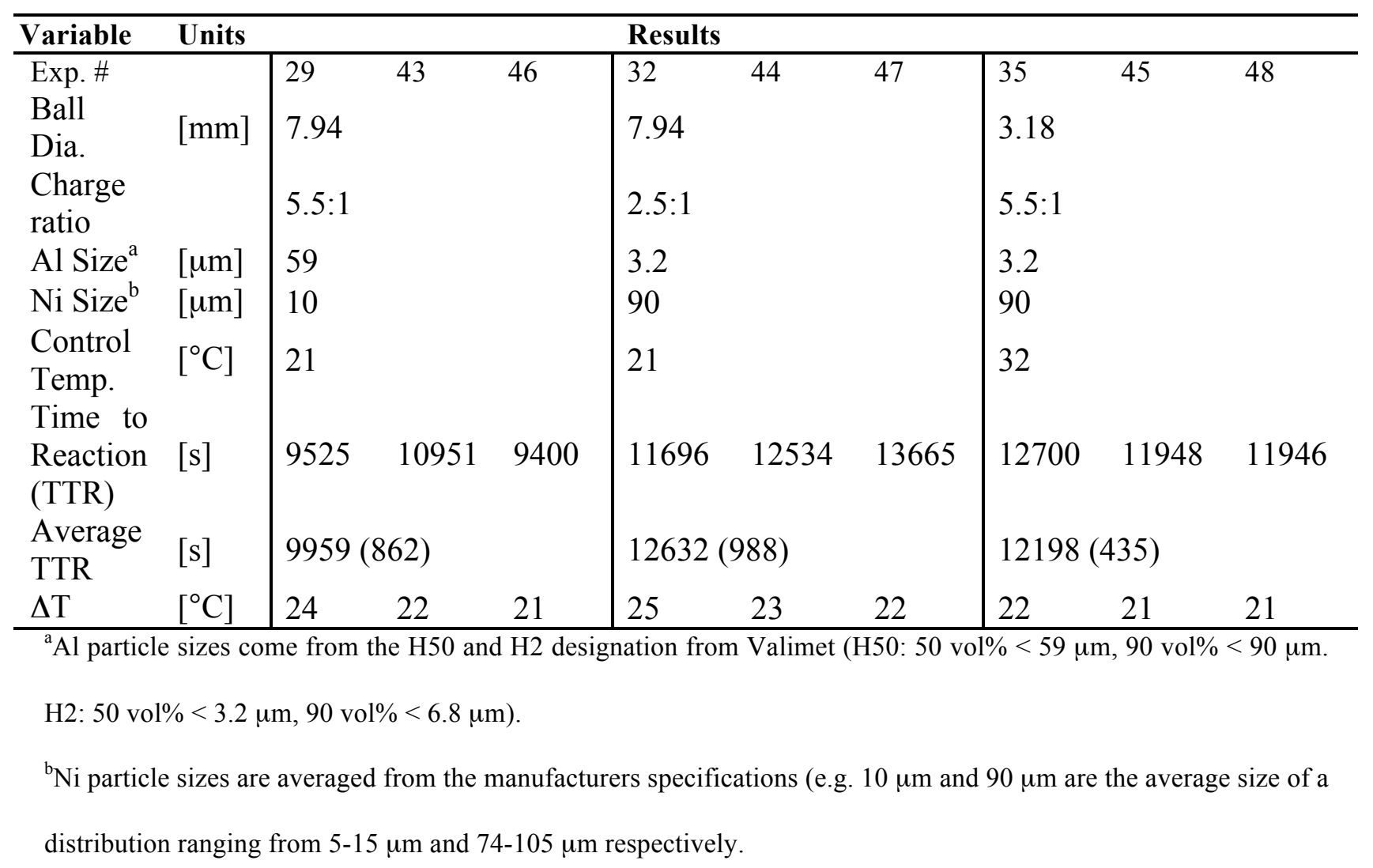


Table 4: Milling measurements for ARM1-ARM3 powders. These powders were milled for a percentage of TTR values listed in Table 3 .

\begin{tabular}{lllllll}
\hline Exp. \# & $\begin{array}{l}\text { Mass } \\
\text { Balls }\end{array}$ & Mass Al & Mass Ni & $\begin{array}{l}\text { Mass } \\
\text { PCA }\end{array}$ & $\begin{array}{l}\text { Mill } \\
\text { (\%TTR) }\end{array}$ & Time \\
\hline & {$[\mathbf{g}]$} & {$[\mathbf{g}]$} & {$[\mathbf{g}]$} & {$[\mathbf{g}]$} & {$[\mathbf{s}]$} \\
\hline 50 & 56.75 & 3.146 & 6.849 & 0.101 & $3486(35)$ \\
51 & 55.76 & 3.146 & 6.850 & 0.101 & $6480(65)$ \\
52 & 25.91 & 3.148 & 6.851 & 0.990 & $4420(35)$ \\
53 & 25.91 & 3.151 & 6.851 & 0.100 & $8210(65)$ \\
54 & 54.99 & 3.149 & 6.850 & 0.101 & $4268(35)$ \\
55 & 54.99 & 3.150 & 6.850 & 0.100 & $7920(65)$ \\
57 & 55.90 & 3.148 & 6.846 & 0.098 & $3486(35)$ \\
58 & 55.69 & 3.150 & 6.850 & 0.097 & $6472(65)$ \\
59 & 25.91 & 3.150 & 6.852 & 0.098 & $4420(35)$ \\
60 & 25.92 & 3.144 & 6.849 & 0.099 & $8210(65)$ \\
61 & 54.99 & 3.151 & 6.856 & 0.100 & $4268(35)$ \\
62 & 54.99 & 3.148 & 6.846 & 0.095 & $7928(65)$ \\
\hline
\end{tabular}


Table 5: Analysis of variance (ANOVA) of the measured time to reaction (TTR) and the change in vial temperature due to intermetallic formation from Table 2 for the designed experiments (DOE) in Table 1 . Column 3 gives the standard error of each term, in their respective units, in Eq. (4) and (5). Columns 2 and 4-7 are given in terms of "coded" factors which scales the range of each variable from -1 to +1 .

\begin{tabular}{|c|c|c|c|c|c|c|}
\hline Source & $\begin{array}{l}\text { Sum of } \\
\text { Squares }\end{array}$ & $\begin{array}{l}\text { Std. Error } \\
\text { of Term }\end{array}$ & $\begin{array}{l}\text { Degrees of } \\
\text { Freedom } \\
\end{array}$ & $\begin{array}{l}\text { Mean } \\
\text { Square } \\
\end{array}$ & F-value & P-value \\
\hline TTR-Model & $3.2410^{8}$ & & 6 & $5.4010^{7}$ & 98.6 & $<1.010^{-4}$ \\
\hline Constant & & \pm 3000 & & & & \\
\hline $\mathrm{A}-\left(d_{b}\right)$ Ball Dia. & $2.5110^{7}$ & \pm 3000 & 1 & $2.5110^{7}$ & 45.9 & $3.010^{-4}$ \\
\hline $\mathrm{B}-\left(r_{b p}\right)$ Charge Ratio & $9.0410^{7}$ & \pm 200 & 1 & $9.0410^{7}$ & 165 & $<1.010^{-4}$ \\
\hline $\mathrm{C}-\left(m_{p}\right)$ Powder Mass & $8.0910^{7}$ & \pm 60 & 1 & $8.0910^{7}$ & 148 & $<1.010^{-4}$ \\
\hline $\mathrm{D}-\left(T_{c}\right) \mathrm{Temp}$ & $6.3210^{6}$ & \pm 30 & 1 & $6.3210^{6}$ & 11.5 & $1.210^{-2}$ \\
\hline $\mathrm{E}-\left(d_{\mathrm{Al}}\right) \mathrm{Al}$ size & $1.9410^{7}$ & \pm 13 & 1 & $1.9410^{7}$ & 35.4 & $6.010^{-4}$ \\
\hline $\mathrm{G}-\left(m_{\mathrm{PCA}} / m_{p}\right) \% \mathrm{PCA}$ & $2.8010^{7}$ & \pm 20000 & 1 & $2.8010^{7}$ & 51.1 & $2.010^{-4}$ \\
\hline Residual & $3.8410^{6}$ & - & 7 & $5.4810^{5}$ & - & - \\
\hline Pure Error & $3.8110^{6}$ & - & 6 & $6.3510^{5}$ & - & - \\
\hline Total & $3.2810^{8}$ & - & 13 & - & - & - \\
\hline$\Delta$ T-Model & 740 & & 7 & 106 & 63.4 & $<1.010^{-4}$ \\
\hline Constant & & \pm 2 & & & & \\
\hline A - $\left(d_{b}\right)$ Ball Dia. & 27.2 & \pm 8 & 1 & 27.2 & 16.3 & $6.810^{-3}$ \\
\hline $\mathrm{B}-\left(r_{b p}\right)$ Charge Ratio & 9.82 & \pm 0.5 & 1 & 9.82 & 5.89 & $5.110^{-3}$ \\
\hline $\mathrm{C}-\left(m_{p}\right)$ Powder Mass & 65.7 & \pm 0.3 & 1 & 65.7 & 39.4 & $8.010^{-4}$ \\
\hline $\mathrm{D}-\left(T_{c}\right) \mathrm{Temp}$ & 13.5 & \pm 0.05 & 1 & 13.5 & 8.10 & $2.910^{-3}$ \\
\hline $\mathrm{E}-\left(d_{\mathrm{Al}}\right) \mathrm{Al}$ size & 13.1 & \pm 0.05 & 1 & 13.1 & 7.83 & $3.110^{-3}$ \\
\hline $\mathrm{F}-\left(d_{\mathrm{Ni}}\right) \mathrm{Ni}$ size & 12.6 & \pm 0.01 & 1 & 12.6 & 7.54 & $3.410^{-3}$ \\
\hline $\mathrm{G}-\left(m_{\mathrm{PCA}} / m_{p}\right) \% \mathrm{PCA}$ & 13.9 & \pm 30 & 1 & 13.9 & 8.36 & $2.810^{-3}$ \\
\hline Pure Error & 10.0 & - & 6 & 1.67 & - & - \\
\hline Total & 750 & - & 13 & - & - & - \\
\hline
\end{tabular}




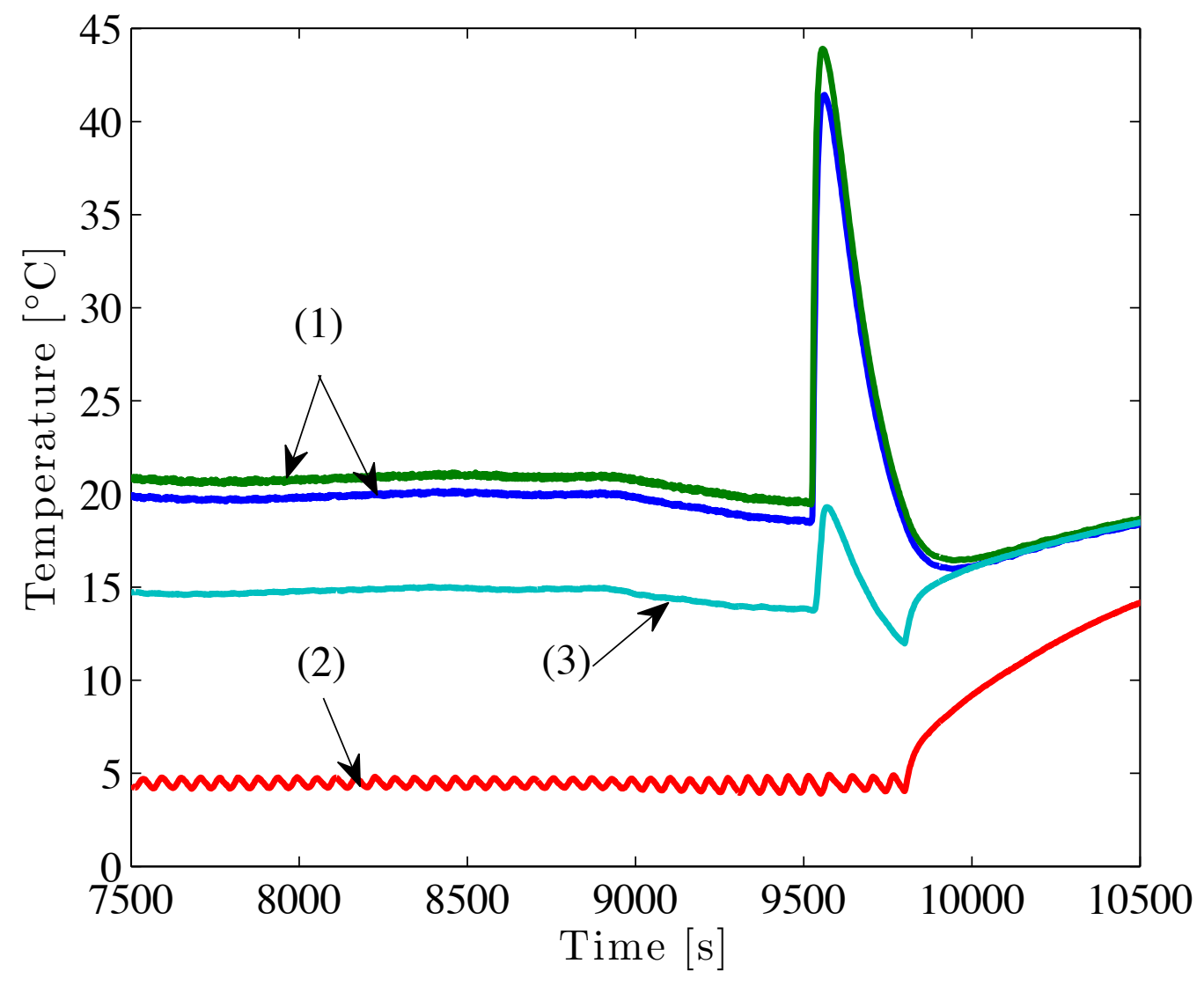

Figure 1: Typical temperature measurements from the thermocouples during ball-milling taken from experiment 29. The two curves marked by (1) are the temperature measured at the bottom (top curve) and top (bottom curve) of the cylindrical vial. The temperature profile of the coolant entering (curve (2)) and leaving (curve (3)) the cooling coil. 


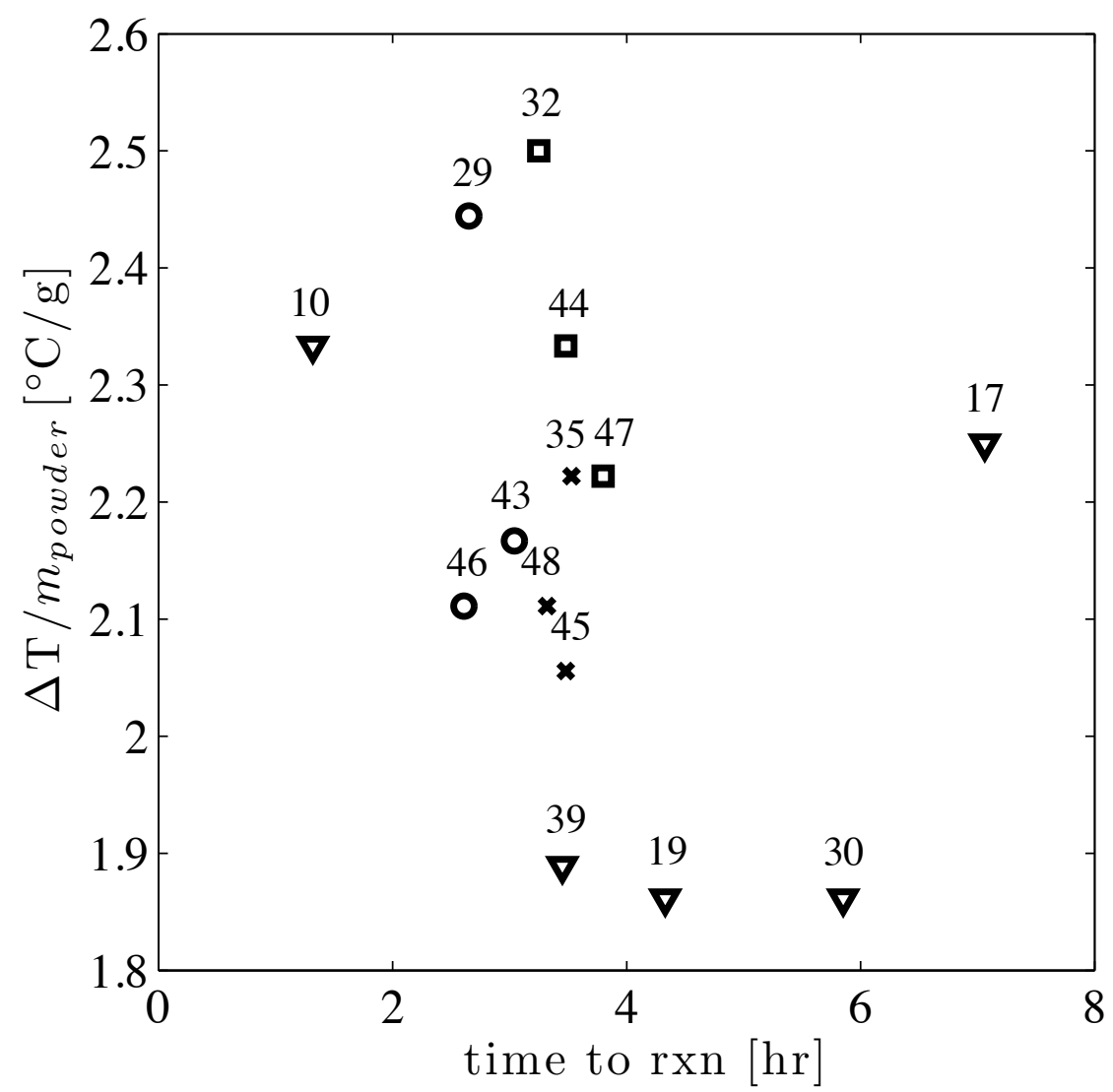

Figure 2: The measured temperature change from reaction during milling is scaled by the mass of the powder and plotted as a function of the time to reaction. The value of $\Delta \mathrm{T}$ is the difference between the maximum temperature and the controlled temperature (see the peak amplitude in Fig. 1). Each data point is labeled with its experimental number for comparison with Tables 1 and 2. The point sets marked with $\bigcirc, \square$, or $\times$ indicate the repetition of experiments 29, 32 and 35, respectively. The $\nabla$ marker indicates the remaining points. Assuming the specific heat is the same for all powders, this figure also indicates the variation in specific energy release detected during reaction, which is approximately $30 \%$. 


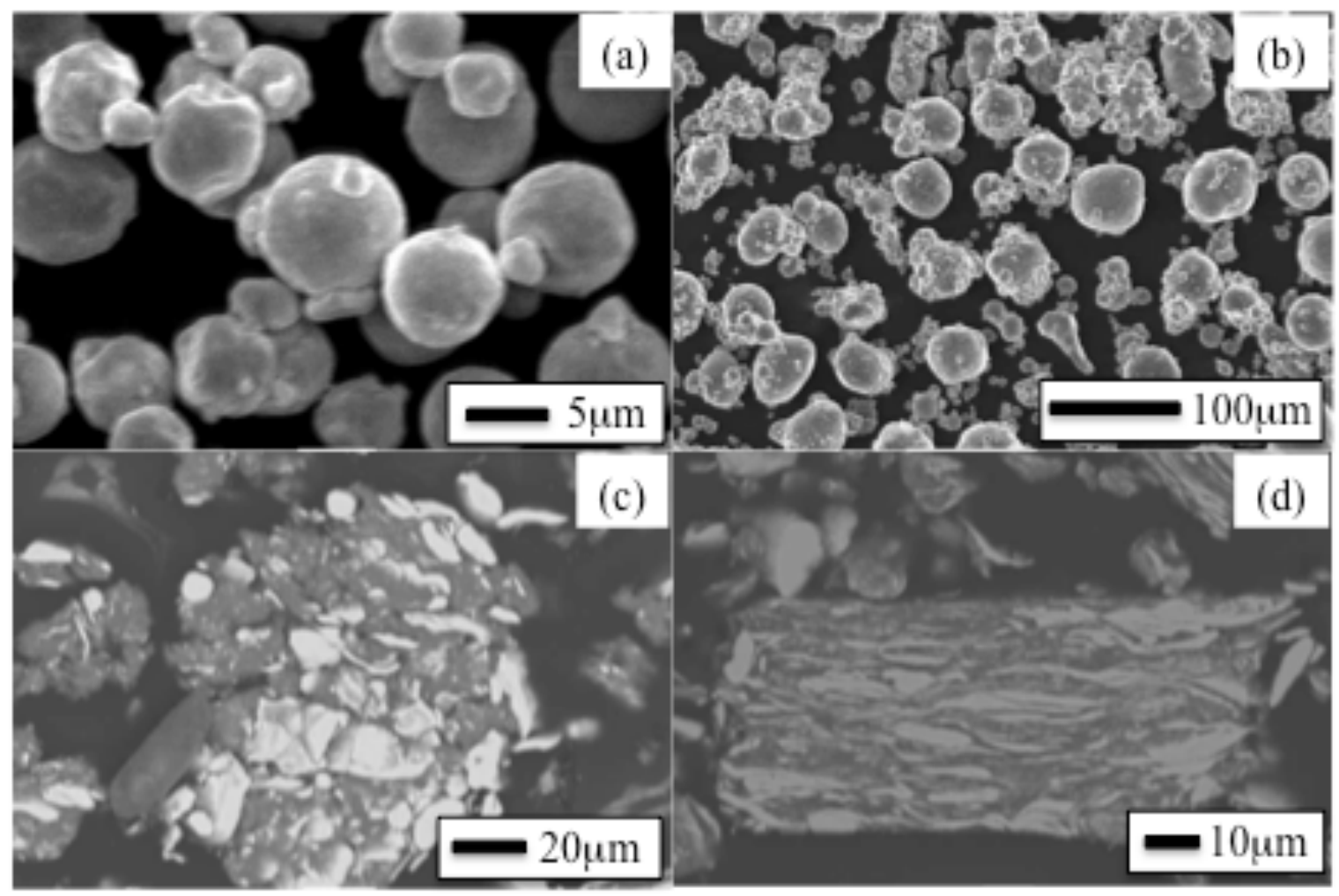

Figure 3: Initial powder morphology and microstructural evolution of powders milled with ARM1 ball-milling conditions (see Tables 1 and 4). (a) 5-15 $\mu \mathrm{m}$ Ni powder. (b) H50 Al powder. (c) Unseived ARM1 powder milled for $35 \%$ TTR (58 min.). The milled particles have significant porosity and some of the Ni (light-gray) particles are only slightly deformed. (d) show unseived ARM1 powder milled for 65\% TTR (108 min.). The porosity observed in (c) is no longer visible and the Ni particles are heavily deformed. 


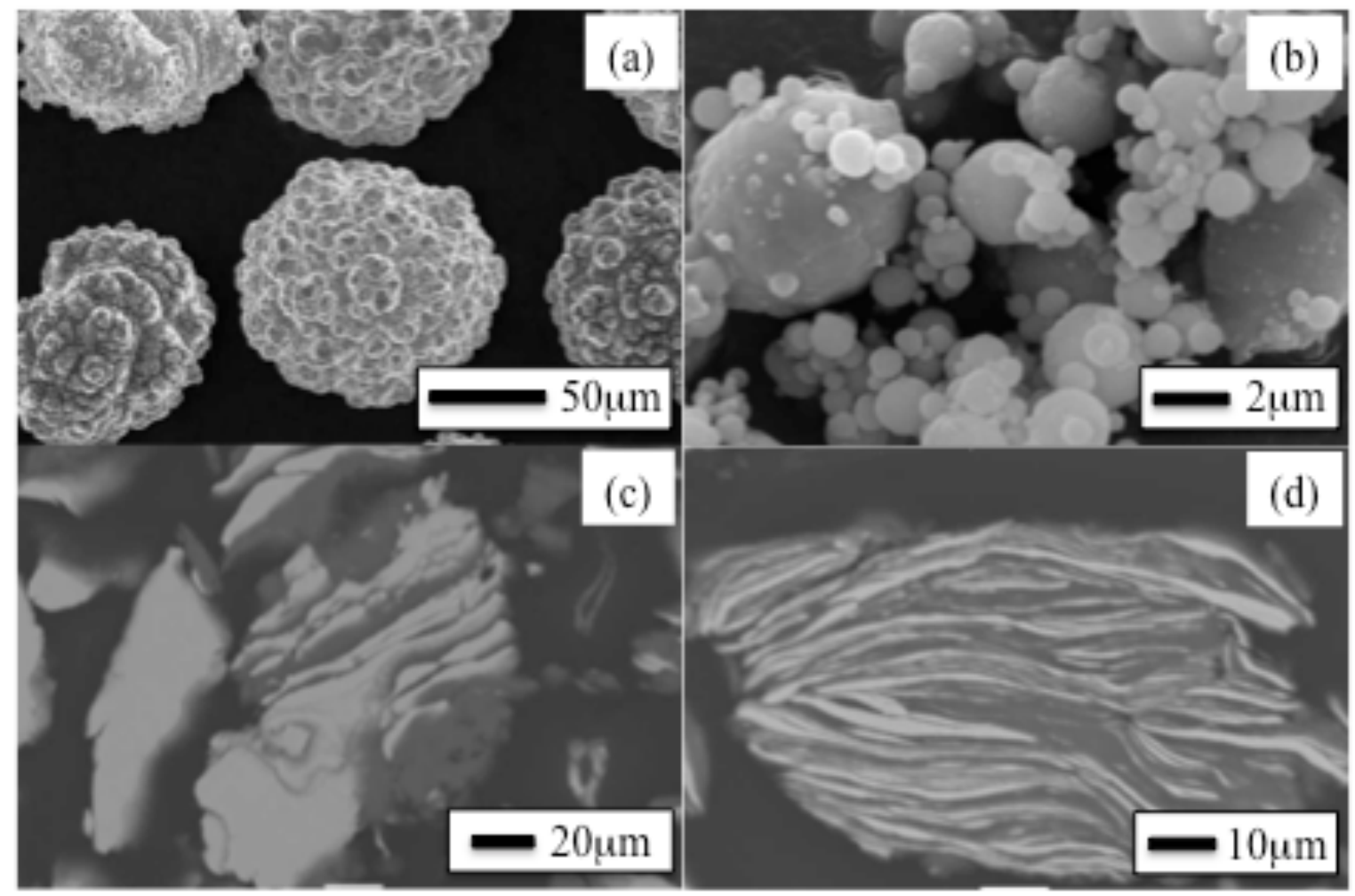

Figure 4: Initial powder morphology and microstructural evolution of powders milled with ARM2 ball-milling conditions (see Tables 1 and 4). (a) and (b) show $100 \mu \mathrm{m} \mathrm{Ni}$ particles and H2 Al particles, respectively. (c) The particle morphology is shown for the powders when milled for $74 \mathrm{~min}$. (35\% TTR). The composite particles are flake-like without visible porosity. (d) The powder particles are shown when milled for $137 \mathrm{~min}$. (65\%). The laminate structure has been refined and the $\mathrm{Ni}$ is dispersed well throughout the particles. 


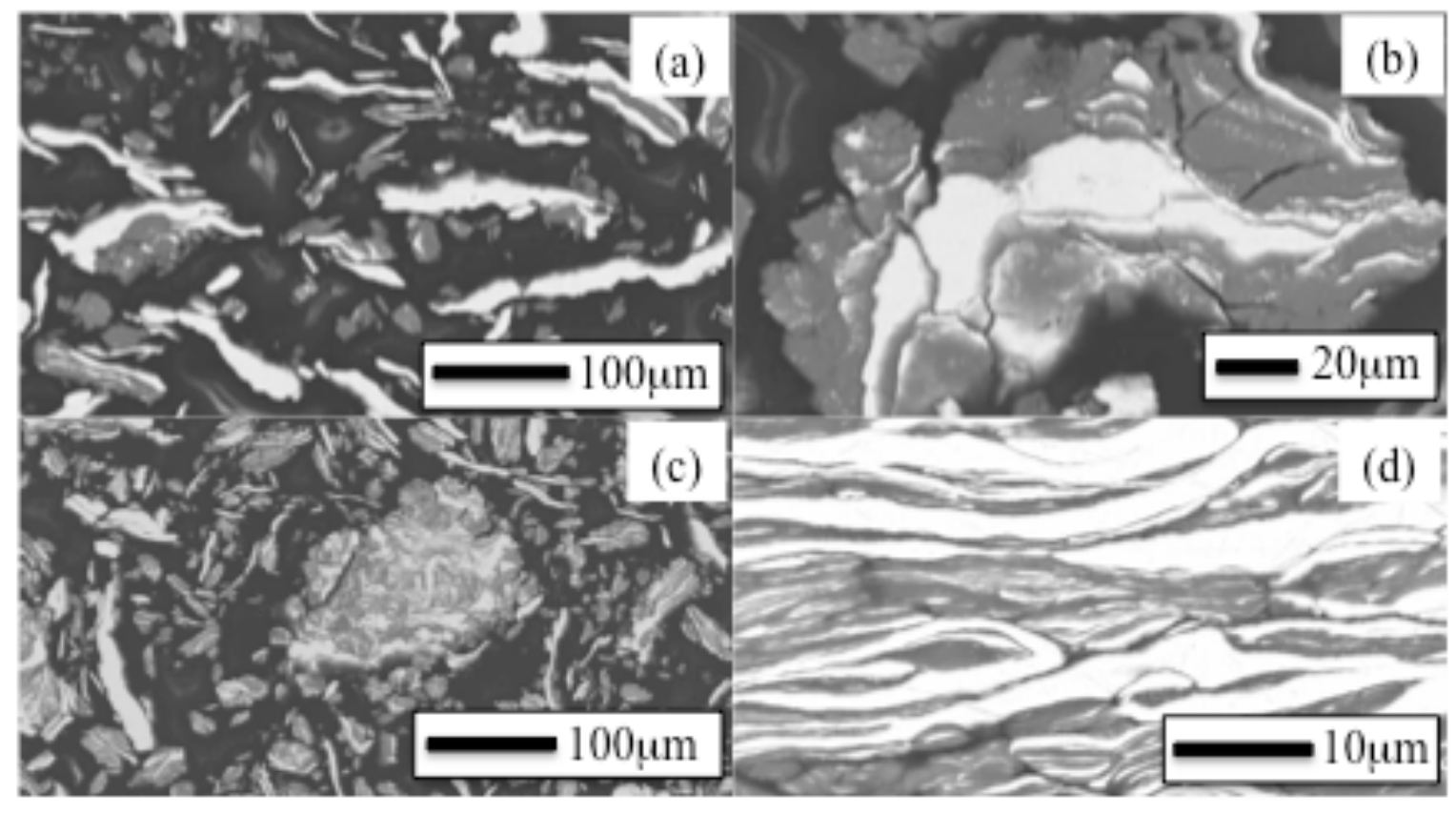

Figure 5: Initial powder morphology and microstructural evolution of powders milled with ARM3 ball-milling conditions (see Tables 1 and 4). (a) and (b) Powder microstructure for powders milled for $71 \mathrm{~min}$. (35\% TTR) with small (light) milling media. The initial powders are identical to (a) and (b) from Fig. 4. Cracks are clearly shown in larger particle agglomerates shown in (b) and the Ni powder is flattened into jagged rod or plate forms. (c) and (d) Powders milled for 132 min. (65\% TTR) showing further reduction of Ni particles. However, cracks and incomplete cold-welding is apparent in the large particle depicted in (d). 


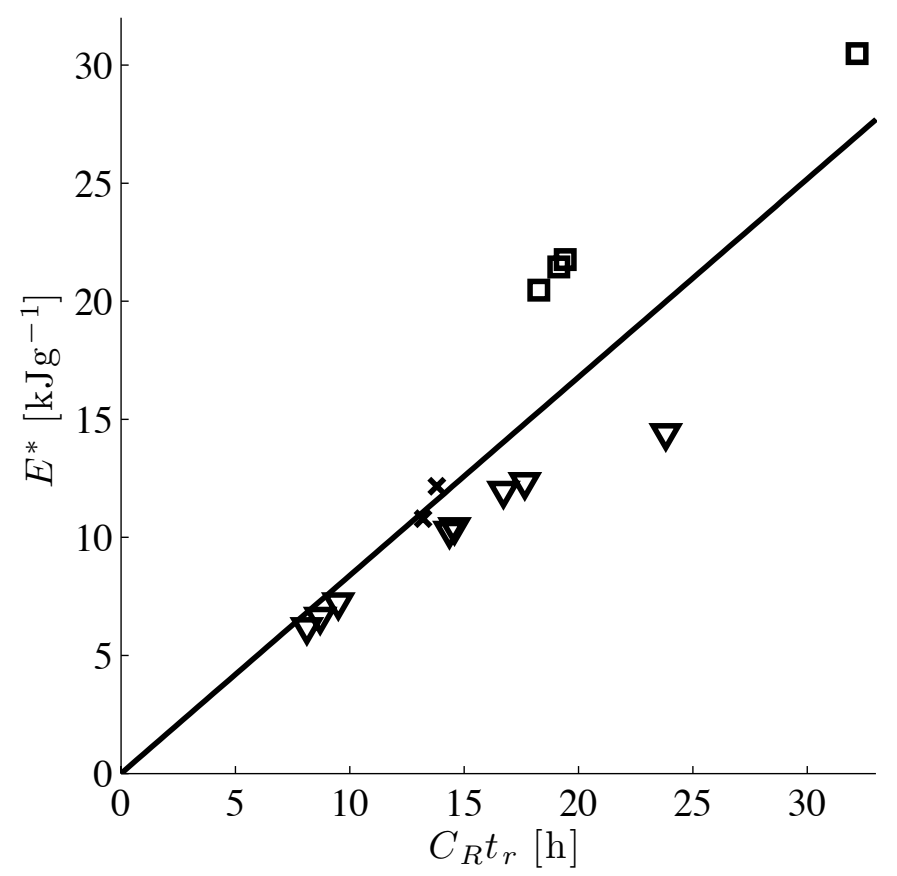

Figure 6: The total energy is plotted as a function of the time to reaction scaled by the charge ratio. The slope of the straight line is given by Eq. (3). The points above this line marked with $\square$ are experiments with the 3.18mm balls. The points marked with $\times$ and $\nabla$ indicate that the $5.56 \mathrm{~mm}$ and $7.94 \mathrm{~mm}$ milling media were used. 

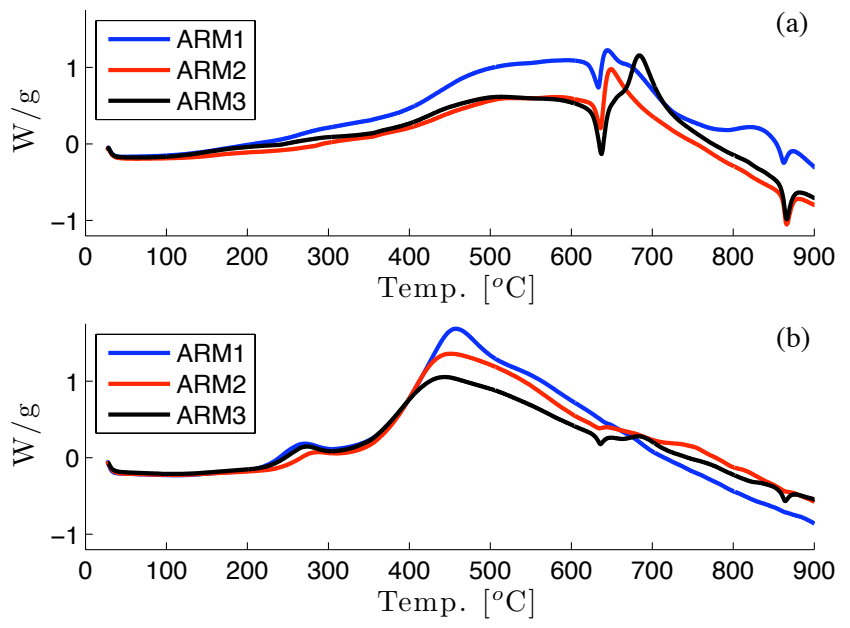

Figure 7: DSC results for the milled powders. (a) Powders from experiments 50, 51 and 52 using ARM1, ARM2 and ARM3 conditions are compared where each is milled for 35\% TTR. The initiation temperature is not clearly defined, but is estimated between $400-450{ }^{\circ} \mathrm{C}$. (b) Powders from experiments 53,54 and 55 using ARM1, ARM2 and ARM3 conditions are compared where each is milled for $65 \%$ TTR. Two distinct reactions are present indicating the difference in reaction kinetics as a function of milling time for similar powders. All scans produced from a heating rate of $20 \mathrm{~K} / \mathrm{min}$. with $110 \mathrm{~mL} / \mathrm{min}$ Ar flow. 

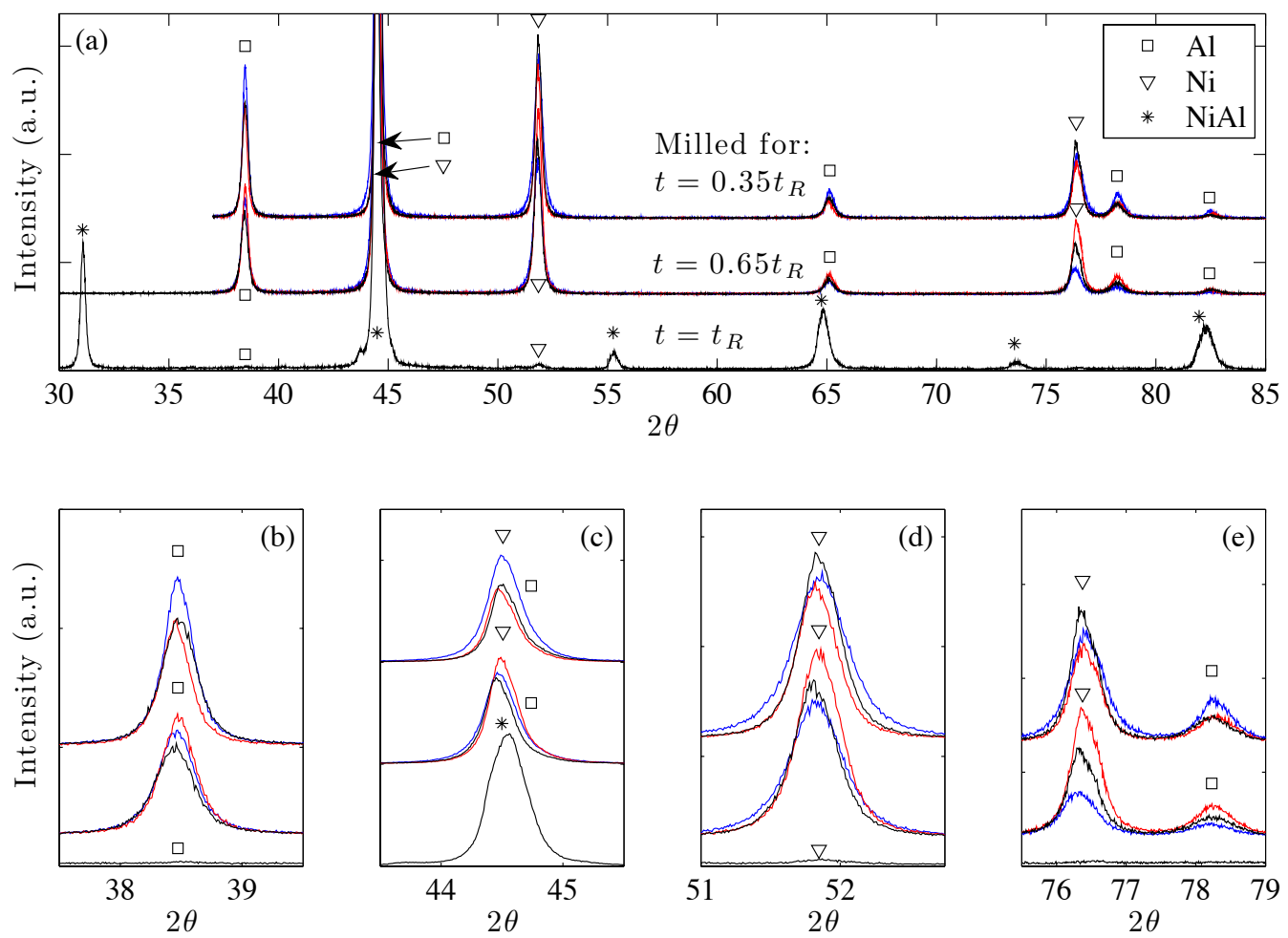

Figure 8: XRD scans for powders six powders milled with ARM1-ARM3 conditions and one from experiment 29 (reacted) shown at the bottom of each subfigure. (a) The top three scans are from powders listed in Table 4 as Exp\# 57 (blue), 59 (red) and 61 (black) corresponding to ARM1-3 conditions milled to 35\% TTR. The middle three scans are from Exp\# 58 (blue), 60 (red) and 62 (black) corresponding to ARM1-3 conditions milled to 65\% TTR. The top, middle and bottom scans are shifted arbitrarily for comparison. (b)-(e) The same seven scans are plotted and shifted vertically to highlight the difference in four different Bragg peaks. The $\square, \nabla$ and * indicate the presence of Al, Ni and $\mathrm{NiAl}$, respectively. 

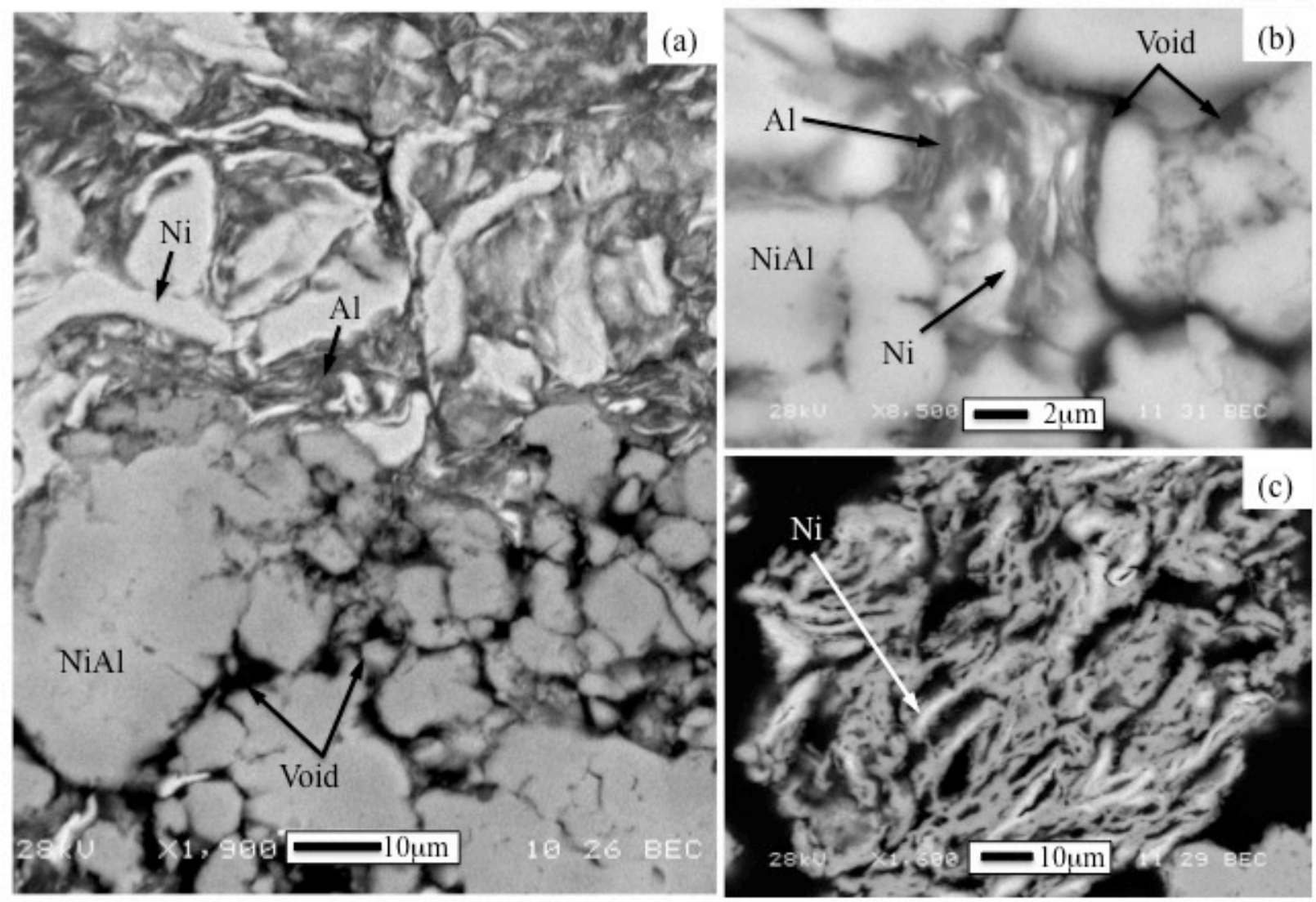

Figure 9: BEC image of partially reacted powder agglomerate for experiment 29. (a) The bottom portion is NiAl and the darker gray is $\mathrm{Al}$ and the light gray is $\mathrm{Ni}$. The NiAl is shown as small separated grains at the bottom of the figure. The reaction propagation moved from the bottom to the top of the image before being arrested. (b) A small amount of powder is completely surrounded by intermetallic NiAl. The reaction sopped along the right side through the separate surfaces, but the propagating reaction ceased during reaction on the left. (c) Arrested reaction within a particle where there is a clear concentration gradient from Ni to NiAl. 